\title{
YAPAY ANAKAYA KULLANILARAK YÜKSEK HIZLI TRENLERİN ALÜVYON ZEMİNLERDEKİ ÇEVRE YAPILARDA OLUŞTURDUĞU TİTREŞİM ETKİLERİNİN AZALTILMASI
}

\author{
Fatih GÖKTEPE ${ }^{1}$, Erkan ÇELEBI ${ }^{2}$, Muharrem AKTAŞ ${ }^{2}$ \\ ${ }^{1}$ Bartın Üniversitesi, İnşaat Mühendisliği Bölümü, Bartın \\ ${ }^{2}$ Sakarya Üniversitesi, İnşaat Mühendisliği Bölümü, Sakarya \\ fgoktepe@bartin.edu.tr, ecelebi@sakarya.edu.tr, muharrema@sakarya.edu.tr
}

(Geliş/Received: 03.09.2014; Kabul/Accepted: 06.04.2016)

ÖZET

\begin{abstract}
Hızlı demiryolu hattına yakın yapıları yumuşak zemin koşullarında taşınan kuvvetli titreşimlerden korumak için dalga bariyeri olarak yapay anakaya modeli inşaat mühendisliğinin pratik uygulamalarında kullanılmaktadır. $\mathrm{Bu}$ çalışmada, yüksek hızlı tren trafiğinin meydana getirdiği titreşimlerin demiryolu ağının çevresindeki binalarda oluşturduğu etkilerin azaltılması için dalga engelleyici bariyerlerin yerleştirilmesi araştırılmıştır. Yapay anakayanın aktif ve pasif yalıtım durumlarına göre performansını değerlendirebilmek için ayrıntılı parametrik çalışmalar gerçekleştirilmiştir.
\end{abstract}

Anahtar Kelimeler: Yapay anakaya, yüksek hızlı tren, alüvyon zeminlerde dalga yayılımı, sonlu elemanlar metodu, doğrusal olmayan malzeme davranışı

\section{USING ARTIFICIAL BEDROCK IN MINIMIZING THE EFFECTS OF VIBRATION INDUCED BY HIGH SPEED TRAINS ON THE NEARBY STRUCTURES IN ALLUVIAL SOILS}

\begin{abstract}
An artificial bedrock as wave impeding barrier can be used in practical civil engineering applications as isolation measures to protect structures from strong vibrations transmitted through soft ground nearby high-speed railway track. This study focuses on mitigation of the effects of high speed trains inducued vibrations on the strucutres which are located near the track lines by installing wave impeding barriers. Extensive parametric studies on the screening performance of wave impeding barrier have been done for both active and passive isolation cases.
\end{abstract}

Keywords: Artificial bedrock, high speed train, wave propagation in alluvial soils, finite element method, nonlinear behaviour of soil

\section{GİRIŞ (INTRODUCTION)}

Tren setlerinin yüksek seyahat hizlarıyla (250-300 $\mathrm{km} / \mathrm{h}$ ) tekrarlı geçişleri sırasında ürettikleri yüksek frekanslı dinamik etkiler ile titreşen demiryolu üstyapısı, dinamik yükleri çevresindeki zeminlere iletirler ve zemin ortamındaki dalga yayılışıyla demiryolu ağına yakın bölgedeki yapılar etkilenir. Kuvvetli yer hareketleri binalara ve temellerine hasar verebileceği gibi bu binalarda yaşayan insanlara da konfor bozucu titreşimleriyle rahatsızlık verir. $\mathrm{Bu}$ nedenle demiryolu üstyapısını ve çevreyi titreşim kaynaklarının ürettiği kuvvetli yer hareketlerinden korumak ihtiyacı ve bu kuvvetli titreşimlerin azaltılması için arazide en uygun yalıtım aracının bulunması çabaları zemin ortamında dalga yayılıșı probleminin iyi anlaşılmasını gerektirir. $\mathrm{Bu}$ alanda kapsamlı ve yoğun araştırmaların gerekliliği, özellikle ülkemizin taşıma gücü zayıf, alüvyon zemin ortamlarından geçirilen yüksek hızlı modern demiryolu hatları (Ankara-İstanbul hızlı tren projesi) için, güncelliğini korumaktadır. Yumuşak zemin koşullarında $200 \mathrm{~km} / \mathrm{h}$ değerlerine ulaşan Rayleigh yüzey dalgasının yayılma hızı, bu tür zayıf zemin koşullarında oluşabilecek rezonans durumuna bağlı olarak çevre yapılarda rahatsızlık verici titreşimlere 
sebep olmaktadır. Bu durumda demiryolu üst yapısını balastlı oluşturmak yerine balastsız rijit yatak olarak inşa etmek, kritik hız değerinin artırılması için alınacak bir önlemdir. Bunun dışında, korunacak yapının etrafina, dalga geliş doğrultusuna dik veya korunacak yapının altına uygun derinlikte yatay olarak elastik veya rijit malzemelerden yapılmış çeşitli yalıtım araçlarının yerleştirilmesi inşaat mühendisliğinin bu tarz problemlerine çözüm olarak uygulanmaktadır. Çözüm önerisi olarak düşünülen dalga engelleyicilerin korunacak yapının yakınında olması durumuna literatürde pasif yalıtım, uzağında olması veya titreşim kaynağına yakın olması durumuna ise aktif yalıtım denilmektedir. Bu çalışmada geliştirilen hesap modeli ile yalıtım performansı sayısal olarak değerlendirilecek olan dalga bariyer modeli yapay taban kaya uygulamasıdır. $\mathrm{Bu}$ yöntem mevcut zemin profilinin yapay olarak altı taban kaya ile sınırlandırılmış tabakalı zemine dönüştürme esasına dayanmaktadır. Zeminin öz frekansları ve buna bağlı titreşim modları yapay kayanın konumlandırılacağı derinlikle kontrol edilerek yönetilmektedir. Böylece dalgaların yayılma mekaniği değiştirilerek titreşimlerin etkileri azaltılmaktadır. $\mathrm{Bu}$ çözüm dış yükün zorlayıcı frekansının zemin tabakasının öz frekansından daha küçük olduğu durumlarda dalga yayılımının ve sonucunda titreşimlerin zemin tabakasında oluşmadı ğ 1 olgusuna dayanarak geliştirilmiştir. $\mathrm{Bu}$ çalışmanın amacı, yalıtım uygulamasında kullanılacak olan yapay taban kaya modelinin ideal yerinin belirlenmesi (aktif veya pasif yalıtıma karar verilmesi), en uygun yapay kaya malzeme özelliklerinin seçilmesidir. Bununla birlikte, bariyer uygulamalarında dikkate alınan en önemli etkenlerden biri olan malzeme yoğunluğu da (empedans kontrastı) araştırılmıştır. Malzeme yoğunluğunun etkisi, nümerik analizlerde farklı malzemeleri temsil eden empedans kontrast değerleri ile dikkate alınmıştır.

\section{LITERATÜR ÖZETİ (REVIEW OF PUBLISHED STUDIES)}

Yüksek frekansta tekrarlı dinamik yüklerden dolayı kuvvetli yüzey dalgalarının neden olduğu büyük genlikli titreşimlerin yakın çevresindeki etkilerini azaltabilmek için korunacak yapı ile titreşim kaynağı arasında malzeme yoğunlukları değişen farklı türlerde geliştirilmiş düşey dalga bariyer modelleri uygulanmaktadır [1-3]. Yatay dalga bariyeri uygulamasıyla da zeminin öz frekansları ve buna bağlı titreşim modları yapay kayanın konumlandırılacağı derinlikle değiştirilerek titreşim etkilerinin azaltılabileceği gösterilmiştir [4-6]. Durağan veya hareketli titreşim kaynaklarının ürettiği zemin dalgalarının davranışını ve yayılışını düşey yalıtım araçlarının performansıyla birlikte daha iyi anlayabilmek için son dönemlerde az sayıda da olsa sahada deneysel çalışmalar ve laboratuvar test düzeneklerinde bir dizi araştırmalar gerçekleştirilmiştir [7-9]. Ayrıca zemine gömülü yatay bariyer modeli ile ilgili ilk arazi deneylerini Forchap ve Verbic [10] pasif ve aktif yalitım durumları için gerçekleştirmişlerdir. Ana kaya özelliğini taşıyan frekans kontrollü bir yapay taban kaya modeli önermişlerdir. Saha deneyleri dışında dalga yayılım problemleriyle ilgili daha gerçekçi hesap modelleri için ileri analitik çözüm yaklaşımları yirminci yüzyılın sonlarında ortaya çıkmıştır [11-13]. Son yirmi yılda bilgisayar teknolojisinin hızl gelişimiyle birlikte dalga yayılım mekaniğinin hareketli yüklere göre daha karmaşık problemlerini çözmek ve yalıtım sistemlerinin etkilerini daha iyi değerlendirebilmek için farklı sayısal çözüm yaklaşımları kullanılmıştır. Bu alanda yapılan önemli çalışmalarda, özellikle farklı zemin formasyonlarının ve gömülü yap1 temellerinin modellenmesinde sonlu elemanlar yöntemi etkin olarak kullanılmıştır. Yarı sonsuz zeminin sonlu elemanlarla ayrıklaştırılmasında kesim noktaları için özel sınır koşulları kullanılarak geometrik sönüm hesaba katılmıştır $[14,15]$. Tüm problemi temsil eden matematik modellerin dinamik çözümlemelerinde radyasyon sönümünü doğrudan hesaba katan sınır elemanlar yöntemi $[16,17]$ ya da bu tekniklerin sonlu elemanlarla ortak çözümlerine dayalı hibrit çözüm olarak isimlendirilen sayısal yaklaşımlar kullanılarak kalibrasyon hassasiyeti yüksek modeller geliştirilmiştir [18, 19]. Fakat gerçekleştirilen sayısal çözümlerden elde edilen sonuçlar özellikle zeminin elastik yarı uzay olarak değerlendirilmesiyle sınırlı kalmıştır.

\section{SONLU ELEMAN MODELININ OLUŞTURULMASI VE DOĞRULANMASI (CONSTRUCTION AND VERIFICATION OF THE FINITE ELEMENT MODEL)}

Yapay taban kaya bariyer modelinin aktif ve pasif yalıtım durumlarına göre performansını değerlendirebilmek için geliştirilen sonlu eleman modeli üzerinde sistematik bir program akışı içersinde çeşitli kontrol parametrelerine bağlı sayısal analizler gerçekleştirilmiştir (Şekil 1). Sonlu eleman analizlerinde gözlem noktaları olarak demiryolu üstyapısının alt tabanı (B noktası) ve binanın çatı katı düzeyi (A noktası) seçilmiştir. İlk aşamada yapay taban kayanın konumlandırılacağı yerin dalga yayılımına etkisi tren seyahat hızları (V) da dikkate alınarak empedans kontrastı (IR) olarak tanımlanan bariyer malzemesinin yoğunluğuna göre incelenmiştir. Dalga bariyer modelinin analizlerde öngörülen optimum kesit boyutları, yazarların Göktepe vd. [20], daha önceki analitik çalışmalarına dayalı belirlendiğinden burada yapay kayanın geometrik özellikleri üzerinde tekrar bir araştırma yapılmamıştır. Sayısal hesaplarda aktif yalıtım durumu için belirlenen ideal model boyutları $\mathrm{H}_{\mathrm{a}}=1 \mathrm{~m}$, $B_{a}=1 m$ ve $L_{a}=7 m$ dikkate alınmıştır. Pasif yalıtım durumu için ise $\mathrm{H}_{\mathrm{a}}=2 \mathrm{~m}, \mathrm{~B}_{\mathrm{a}}=1 \mathrm{~m}$ ve $\mathrm{L}_{\mathrm{a}}=14 \mathrm{~m}$ değerleri kullanılmıştır. Ayrıca farklı tren geçiş hızlarında demiryolu balast yatağı rijitliğinin (E) 
demiryolu üstyapısı titreşimine etkileri araştırılmıştır. Analizlerde dinamik davranışı incelenen yapı modeli, 1,5 $\mathrm{m}$ temel derinliğinde 6 katlı 3 açıklıklı betonarme düzlem bir çerçevedir. Binanın yüksekliği $18 \mathrm{~m}$ genişliği ise $12 \mathrm{~m}$ 'dir. Yapının yük kaynağından uzaklığı $20 \quad \mathrm{~m}$ olarak seçilmiştir. Demiryolu platformunun üst taban genişliği $6 \mathrm{~m}$, alt taban genişliği $8 \mathrm{~m}$ ve zeminden yüksekliği 1,5 m olarak belirlenmiştir.

\subsection{Tren Yükünün Simülasyonu (Simulation of Train Load)}

Hizlı tren setinin zamana ve konuma bağlı yük dağılımının sayısal modele katılması analiz sürecinin en önemli aşamasını oluşturmaktadır. Bu çalışmada hareketli yük seti olarak sadece lokomotifin kendisi dikkate alınmıştır. Lokomotifin öz ağırlığı dingiller aracılığıyla raylara aktarılmaktadır. Vagon ağırlığının lokomotif ağırlığına kıyasla daha hafif olması ve zemin titreşimlerine olan etkisinin az olması sebebiyle vagon etkileri nümerik analizlerde dikkate alınmamıştır. Demiryolu üstyapısı elastik yataklı kiriş olarak modellenirken, tekerlek yükü bu sürekli kiriş üzerinde sabit hizla noktasal hareket eden bir kuvvet olarak idealize edilmiştir [21]. Bu modelde hızlı tren dingil yükü, dingil açıklıkları ve hareket hızıyla; üstyap1 ise belli bir eğilme rijitliği olan raylar ve traverslerin yatak katsayılarıyla karakterize edilmiştir [22]. Demiryolu üstyapısı ve taşıtına ait mekanik özellikler Tablo 1'de özetlenmiştir. Almanya'nın yüksek hızlı demiryolu hatlarında (ICE) kullanılan ağırlığı $1200 \mathrm{kN}$ ve altı dingilli olan lokomotifin (Lok. 103) geçişleri farklı hızlar $\left(\mathrm{V}_{1}=180 \mathrm{~km} / \mathrm{h}\right.$, $\mathrm{V}_{2}=360 \mathrm{~km} / \mathrm{h}$ ) dikkate alınarak analizler yürütülmüştür.

Şekil 2'de sadece seyahat hızı $\mathrm{V}_{1}=180 \mathrm{~km} / \mathrm{h}$ olan lokomotif yükünün traverslerdeki zamana bağlı etkisi gösterilmiştir. Yüksek hız trenlerinin farklı geçiş hızlarına göre tekerlek yüklerinin elde edilmesi ve bunlara ait analitik çözümlerin teorik altyapısı daha önceki çalışmalarda detaylı verildiğinden dolayı burada tekrar bahsedilmemiştir [21-23].

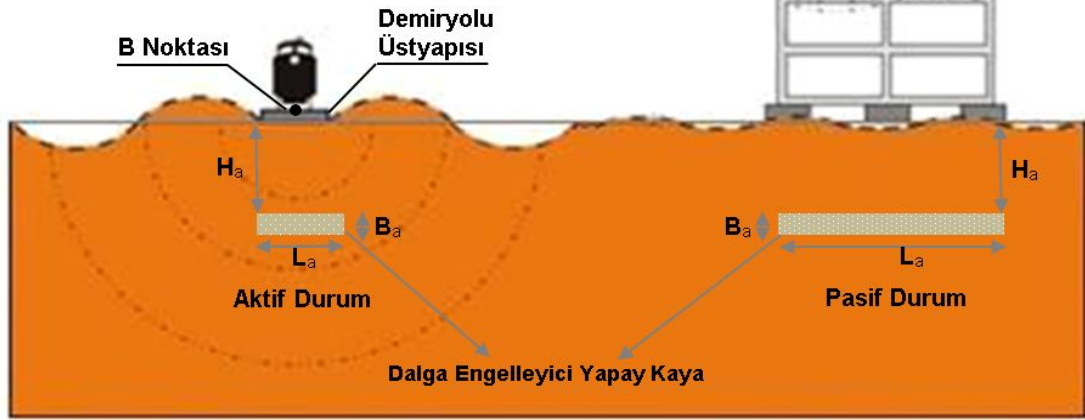

Şekil 1. Üstyapı titreşimlerinin yalıtımı için yapay anakaya modeli (Artificial bedrock model for vibration isolation of structures)

Tablo 1. Demiryolu taşıtı ve hattının mekanik özellikleri (Mechanical characteristics of the railway vehicle and the track)

\begin{tabular}{llccc}
\hline Bileşenler & Karakteristikler & Semboller & Büyüklük & Birim \\
\hline Lokomotif & Dingil yükü & $F_{z}$ & 200 & $\mathrm{kN}$ \\
Loc103 & Hareket hızları & $V$ & 180,360 & $\mathrm{~km} / \mathrm{h}$ \\
\hline Demiryolu & & & & \\
2UIC 60 & & & & \\
\hline & Kesit alanı & $A_{r}$ & $1,54 \times 10^{-2}$ & $\mathrm{~m}^{2}$ \\
& Atalet momenti & $I_{z}$ & $6,11 \times 10^{-5}$ & $\mathrm{~m}^{4}$ \\
& Elastisite modulü & $E$ & $2,11 \times 10^{8}$ & $\mathrm{kN} / \mathrm{m}^{2}$ \\
& Birim hacim ağırlık & $\gamma$ & 78 & $\mathrm{kN} / \mathrm{m}^{3}$ \\
\hline Balast & & & & \\
Yay-söndürücü sistem & Rijitlik katsayısı & $k_{b}$ & $1,26 \times 10^{5}$ & $\mathrm{kN} / \mathrm{m}$ \\
& Sönüm katsayısı & $c_{b}$ & $1,69 \times 10^{2}$ & $\mathrm{kNsn} / \mathrm{m}$ \\
\hline
\end{tabular}




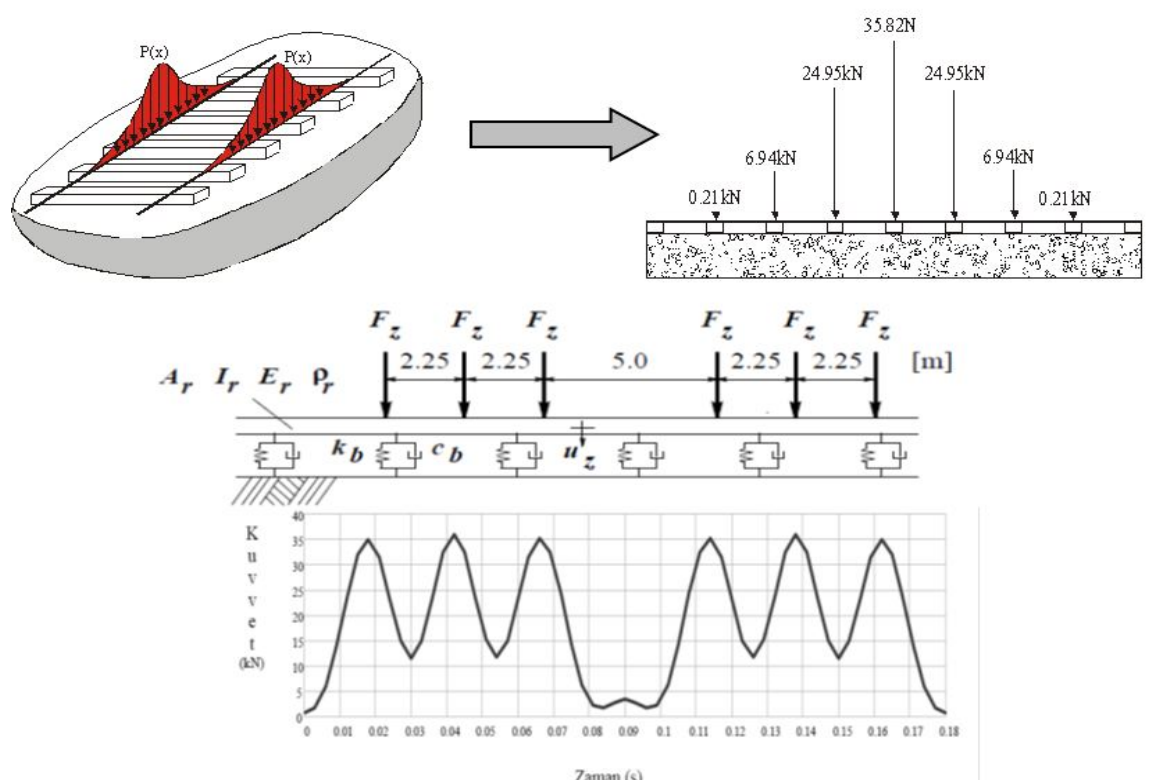

Şekil 2. Analitik model ve dingil yüklerinin zamana bağlı değişimi $\left(\mathrm{V}_{1}=180 \mathrm{~km} / \mathrm{h}\right)$ ((Analytical model and time history of the axle loads for $\mathrm{V}_{1}=180 \mathrm{~km} / \mathrm{h}$ ))

\section{2 Üstyapı ve Zemin için Malzeme Davranış Modelleri (Material Constitutive Models for Soil and Structure)}

Hareketli yükün simülasyonuyla birlikte değerlendirilen üstyapı-zemin ortak sisteminin zaman bölgesindeki çözümü için sonlu elemanlar yöntemine dayalı Plaxis 2D [24] bilgisayar programından yararlanılmıştır. Geliştirilen matematik modelde demiryolu altyapısını oluşturan zeminin öngörülen mekanik davranışı elasto-plastik Mohr Coulomb malzeme modeli ile benzeştirilerek dikkate alınmıştır. Zemin malzeme parametreleri ve analizlerde kullanılan değerleri Tablo 2'de gösterilmiştir. Modelde demiryolu platformu ve bina türü yapının malzeme davranış özellikleri doğrusal elastik olarak ele alınmıştır. Üstyapıların mekanik özelliklerine ait bilgiler yazarların daha önceki çalışmalarında verilmiştir [20]. Sistemin üstyapı-zemin yatay arakesitinde ve dalga yalıtım bariyeri-zemin arakesitinde dinamik etkileşimi rasyonel bir yaklaşımla idealize edebilmek için arayüz dayanım azaltma katsayısı ( $\left.\mathrm{R}_{\text {inter }}\right)$ kullanılmıştır. Etkileşim yüzeyinde küçük deformasyonların oluşabileceği elastik ve kalıcı deformasyonların oluşabileceği plastik davranışı ayırt etmek için Coulomb kıstasından yararlanılmıştır. Plastik davranış için kayma gerilmesi $(\tau)$;

$|\tau|=\sigma_{n} \tan \emptyset_{i}+c_{i}$

şeklinde verilmektedir. Burada $\emptyset_{i}$ ve $c_{i}$ sırasıyla ara yüzeyin içsel sürtünme açısını ve kohezyon değerinin göstermektedir. Ara kesit özellikleri kendisini çevreleyen malzeme özelliklerine ve ortak mukavemet azaltma faktörü bağlı aşağıda verilen kurallara göre hesaplanır:

$$
\begin{aligned}
& c_{i}=R_{\text {inter }} C_{\text {zemin }} \\
& \tan \emptyset_{i}=R_{\text {inter }} \tan \emptyset_{\text {zemin }} \leq \tan \emptyset_{\text {zemin }} \\
& \omega_{i}=0^{\circ} \text { için } R_{\text {inter }}<1, \text { aksi durumda } \omega_{i}=\omega_{\text {zemin }}
\end{aligned}
$$

Genelde, gerçek yapı-zemin dinamik davranışında ara yüzey kendini çevreleyen zemine göre daha zayıf ve daha elastik davranış gösterdiğinden mukavemet özellikleri kendilerini çevreleyen zemininkinden daha düşük değerde $\left(\mathrm{R}_{\text {inter }} \leq 1\right)$ olması gerekir. $\mathrm{Bu}$ çalışmada mukavemet değeri $R_{\text {inter }}=0.67$ alınarak analizler gerçekleştirilmiştir. Yapısal çözümlemelerin hızlı ve öngörülen doğrulukta gerçekleşebilmesi için sistemin geometrik ve malzeme özelliklerinin tren yükünün hareketi doğrultusunca değişmediği kabulü altında düzlem şekil değiştirme problemi olarak 2D sonlu elemanlar modeli benimsenmiştir.

belirlenmiştir.

\subsection{Sonlu Eleman Analizinde Sayısal Doğruluk ve Stabilite (Numerical Accuracy and Stability in the Finite} Element Analysis)

Yapı-zemin dinamik etkileşimi için geliştirilen matematik simülasyonun doğruluk düzeyini iki temel parametre; kullanilan sonlu eleman boyutu ve çözümde dikkate alınan zaman adım aralığı belirlemektedir. Nümerik modellerde kullanılan sonlu eleman boyutunun $(\Delta \mathrm{h})$ üst değeri en kısa dalga boyuna $\left(\lambda_{\text {min }}\right)$ göre sinırlandırılmıştır [25]. En kısa dalga boyu hesaplanırken, dış yükün titreşim frekansı yüksek hızlı trenler için 0-20 Hz olarak dikkate alınmıştır. Yapısal davranışın birinci dereceden önem kazandığı plastik şekil değiştirmenin beklendiği zemin parçası $\left(\mathrm{H}_{1}=10 \mathrm{~m}, \mathrm{~B}_{1}=50 \mathrm{~m}\right)$ küçük boyutlu sonlu elemanlarla $(\Delta \mathrm{h}=0.75 \mathrm{~m})$ modellenmiştir. Yakın bölgeden uzaklaştıkça kullanılan sonlu eleman boyutları büyütülerek sırasıyla $\mathrm{H}_{2}=30 \mathrm{~m}, \mathrm{~B}_{2}=110 \mathrm{~m}$ 
Tablo 2. Zemin ortamının mekanik özellikleri (Mechanical properties of the soil medium)

\begin{tabular}{lccc}
\hline Parametre & Sembol & Büyüklük & Birim \\
Zemin türü: Kum & & & $\left(\mathrm{kN} / \mathrm{m}^{3}\right)$ \\
\hline Birim hacim ağırlık & $\gamma$ & 20 & $\left(\mathrm{kN} / \mathrm{m}^{2}\right)$ \\
Elastisite modülü & $E$ & 53100 & $\left(\mathrm{kN} / \mathrm{m}^{2}\right)$ \\
Kayma modülü & $G$ & 20420 & - \\
Poisson oranı & $v$ & 0,30 & $\mathrm{~m} / \mathrm{s}$ \\
Basınç dalgası & $V_{p}$ & 187 & $\mathrm{~m} / \mathrm{s}$ \\
Kayma dalgası & $V_{s}$ & 100 & - \\
Boşluk oranı & $e$ & 0.80 & $\left(\mathrm{kN} / \mathrm{m}^{2}\right)$ \\
Kohezyon & $c$ & 0 & $\left({ }^{\circ}\right)$ \\
Kayma mukavemeti açısı & $\varnothing$ & 28 & $\left({ }^{\circ}\right)$ \\
Kabarma açıs & $\psi$ & 0 & - \\
Arayüz dayanım azaltma faktörü & $R_{\text {inter }}$ & 0,67 & \\
\hline
\end{tabular}

için $\Delta \mathrm{h}=2 \mathrm{~m} ; \mathrm{H}_{3}=50 \mathrm{~m}, \mathrm{~B}_{3}=200 \mathrm{~m}$ için $\Delta \mathrm{h}=4,5 \mathrm{~m}$ olarak belirlenmiştir (Şekil 3). Hesaplama yükü ve buna bağlı olarak analiz süreci dengelenmiştir. Sayısal çözümlemelerde kullanılan zaman artımının $(\Delta t)$ en büyük değeri Courant ölçütü $(c \leq 1)$ olarak tanımlanan kararlılık koşulunun göz önünde bulundurulmasıyla belirlenmiştir [26].

$\frac{v_{j} \Delta_{t}}{\Delta_{h}}=c$

Burada $\mathrm{v}_{\mathrm{j}}$ problemde dikkate alınan dalganın yayılma hızını göstermektedir. Farklı dalga türlerini hesaba katıldığ1 zemin titreşim problemlerinin analizinde zaman artımı $(\Delta \mathrm{t})$, ortamdaki dalganın en büyük yayılma hızıyla belirlenirken, kullanılacak sonlu eleman boyutunun en küçük dalga hızına bağlı olduğuna dikkat etmek gerekir. Yönetici denklemlerin sayısal integrasyonunda zaman adımı $\Delta \mathrm{t}=0,0103 s n$ alınarak analizler yürütülmüştür.

\subsection{Viskoz Sönümleyici Sınırlar ve Histeretik Sönüm (Viscous Absorbing Boundaries and Hysteretic Damping)}

Dalga yayılım probleminin sonlu eleman simülasyonunda titreşim dalgalarını model sinırlarında serbest bırakmak ve yayılan enerjiyi bu kesim noktalarında tüketmek için literatürde viskoz sönümleyici elemanlar [27] ve sonsuz elemanlar [28, 29] ile yapılan çalışmalar bulunmaktadır. $\mathrm{Bu}$ çalışmada kullanılan sınır şartlarına ait bilgiler yazarların daha önceki çalışmasında [3] detaylı olarak verilmiştir. Eğer ayrıklaştırılan bölgenin sınırları yeterli derecede uzakta seçilmemişse, bölgenin kesim noktalarında geçirgen (soğurgan) sınırlar kullanılsa bile, tam geçirimlilik sağlanamadığından dolayı uzaklaşan ve yansıyan dalgaların çakışmasından analiz sonuçlarında beklenmedik sayısal belirsizlikler ortaya çıkabilmektedir. Yapılan çalışmalar sınır yerlerinin temel taban genişliğinin 8-10 katı kadar uzaklıkta düzenlenmesi ile oluşabilecek sayısal belirsizliklerin giderilebileceğini göstermektedir [28]. Kullanılan sayısal modelin sınırlarında oluşabilecek yansımaların etkisini yok etmek için yapay sönümleyiciler yapının sağ tarafindan $102 \mathrm{~m}$, sol tarafindan $88 \mathrm{~m}$ sınırlara uzakta olacak şekilde yerleştirilmiştir. Geliştirilen çözüm yönteminde sistemden dişarıya doğru yayılan ve zeminin sonsuzluğu nedeni ile zemin ortamında kaybolan enerjiyi tanımlamak için bölgenin sınırlarında eşdeğer anlamda kullanılan, radyasyon sönümü adı verilen ve malzeme sönümü ile ilgisi bulunmayan bir sönüm mekanizması kullanılmıştır (Şekil 3).

\subsection{Modelin Doğrulanması (Model Verification)}

Dalga yayılışının incelendiği sürekli ortam mekaniğinde sistemin sonlu eleman ağ yapısının sıkılığı hassas bir yaklaşımla düzenlenirken problemin sınır özelliklerinin de aynı hassasiyetle doğru tanımlanması hem öngörülen doğruluk düzeyine erişebilme hem de çözüm sürecinin hesap yüküne bağlı olarak dengelenebilmesi açısından son derece önemlidir. Modelin doğrulanması işlemi iki şamada gerçekleştirilmiştir. Öncelikle yazarların daha önceki çalışmaları ile kullanılan sayısal model, zeminin serbest yüzeyindeki düşey yerdeğiştirmelerin $\left(\mathrm{u}_{\mathrm{y}}\right)$ zamana bağlı değişimleri incelenerek karşılaştırılmış [30] ve nümerik analizlerde kullanılacak sonlu eleman modelinin genişliği $\mathrm{B}=200 \mathrm{~m}$ ve derinliği ise $\mathrm{H}=50 \mathrm{~m}$ olacak şekilde belirlenmiştir. Ayrica, Modelin doğrulanması işlemi Amick ve Gendreau [31] tarafindan geliştirilen Bornitz'in iki nokta arasındaki enerji azalımı ile ilgili olarak sunmuş olduğu teorik formülasyon kullanılarak da gerçekleştirilmiştir. Bu teoriye göre, geometrik ve malzeme sönümünün yerdeğiştirme genliklerinde neden olduğu azalım aşağıdaki formülasyon kullanılarak ifade edilmektedir. Buna göre, yük kaynağından $r_{b}$ mesafesindeki yerdeğiştirme genliği $u_{b}$ ile, $r_{a}$ mesafesindeki yerdeğiştirme genliği ise $u_{a}$ ile ifade edilmektedir.

$u_{b}=u_{a}\left(\frac{r_{a}}{r_{b}}\right)^{\gamma} e^{\alpha\left(r_{a}-r_{b}\right)}$

Formülasyondaki, $\gamma$ geometrik azalım katsayısı olup, dış yükün neden olduğu sismik dalga yayılım mekanizmasına ve dış yükün pozisyonuna bağlı olarak Tablo 3'den seçilmektedir [32]. 


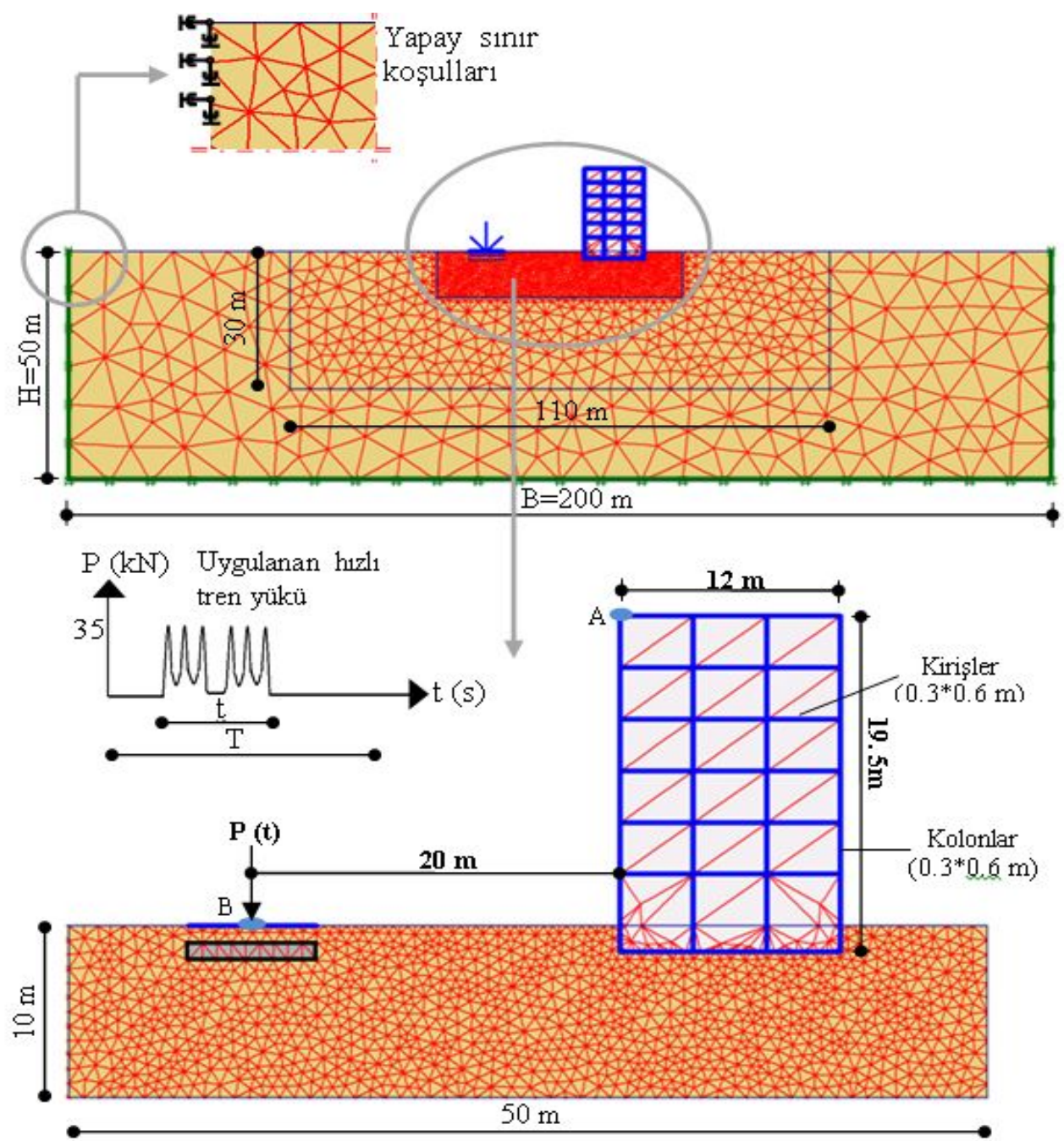

Şekil 3. Yapı-zemin etkileşim problemi için sonlu eleman modeli (Finite element model for the soil-structure interaction problem)

Tablo 3. Dalga tipine bağlı olarak teorik geometrik azalım katsayıları (Summary of theoretical geometric attenuation coefficients based on wave type)

\begin{tabular}{llll}
\hline Yük Kaynağı & Dalga Tipi & $\begin{array}{l}\text { Ölçüm } \\
\text { Noktası }\end{array}$ & $\gamma$ \\
\hline Yüzeysel & Rayleigh & Yüzey & 0,5 \\
Yüzeysel & Rayleigh & Yüzey & 1 \\
Derin & Body & Yüzey & 1 \\
Derin & Body & Derin & 1 \\
\hline
\end{tabular}

$\alpha$ ile gösterilen malzeme azalım katsayısı ise, zeminin tipine ve dış yükün frekans içeriğine bağlı olarak aşağıdaki formülasyon kullanılarak hesaplanmaktadır.

$\alpha=\frac{2 \pi f D}{V_{R}}$

Yerdeğiştirme genliklerinde elde edilen azaltma oranları, yapı-zemin ortak sisteminin dalga yayılım problemi için önerilen sonlu eleman çözümü ile Bornitz analitik yaklaşımı için Şekil 4'de verilmiştir. Elde edilen grafiklerin uyum içersinde olması önerilen modelin doğruluğunu bir kez daha kanıtlamıştır.

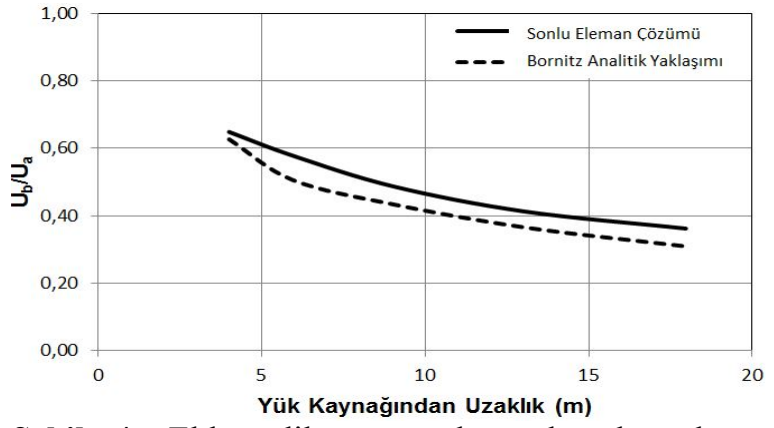

Şekil 4. Elde edilen sonuçların karşılaştırılması (Comparative study of obtained results)

\section{SAYISAL UYGULAMA VE ANALIZ SONUÇLARI (NUMERICAL APPLICATION AND ANALYSIS RESULTS)}

Yapay taban kaya bariyer modelinin aktif ve pasif yalıtım performansı değerlendirilerek, seçilen ölçüm noktalarındaki dinamik etkileri çeşitli kontrol parametrelerine bağlı karşılaştırmalı olarak sunulmuştur (Şekil 5-8). Düzlem şekil değiştirme problemi için 30125 düğüm noktasına atanan bilinmeyenleri kapsayan denklemlerin çözümü yapılmıştır. 

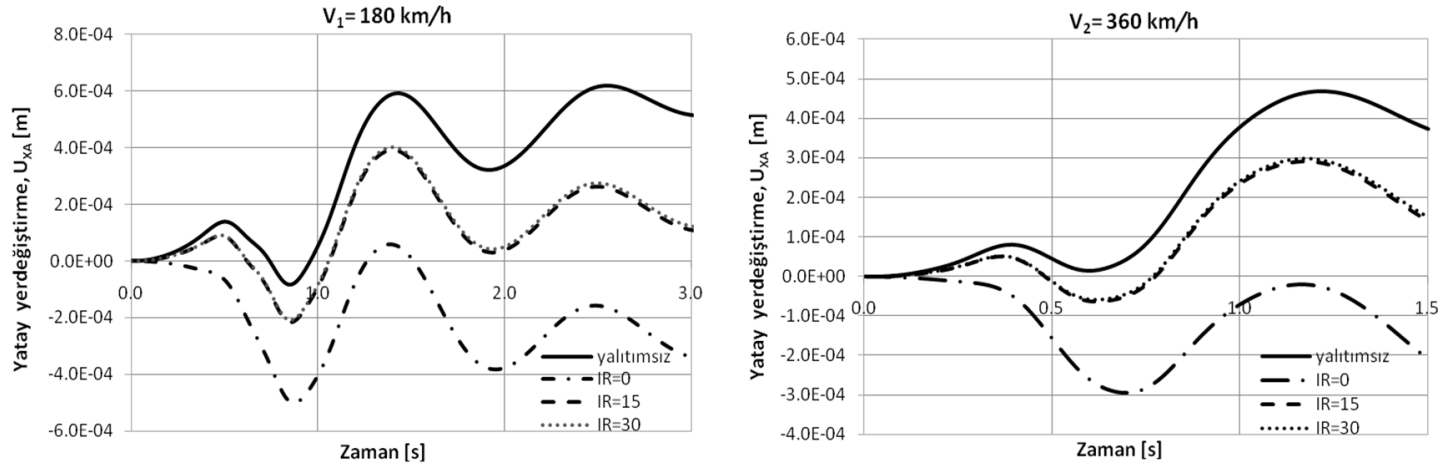

Şekil 5. Bina tepe noktası yatay yerdeğiştirmesinin zaman geçmişi (aktif yalıtım) (Time history of the horizontal roof displacement of the building for active isolation)
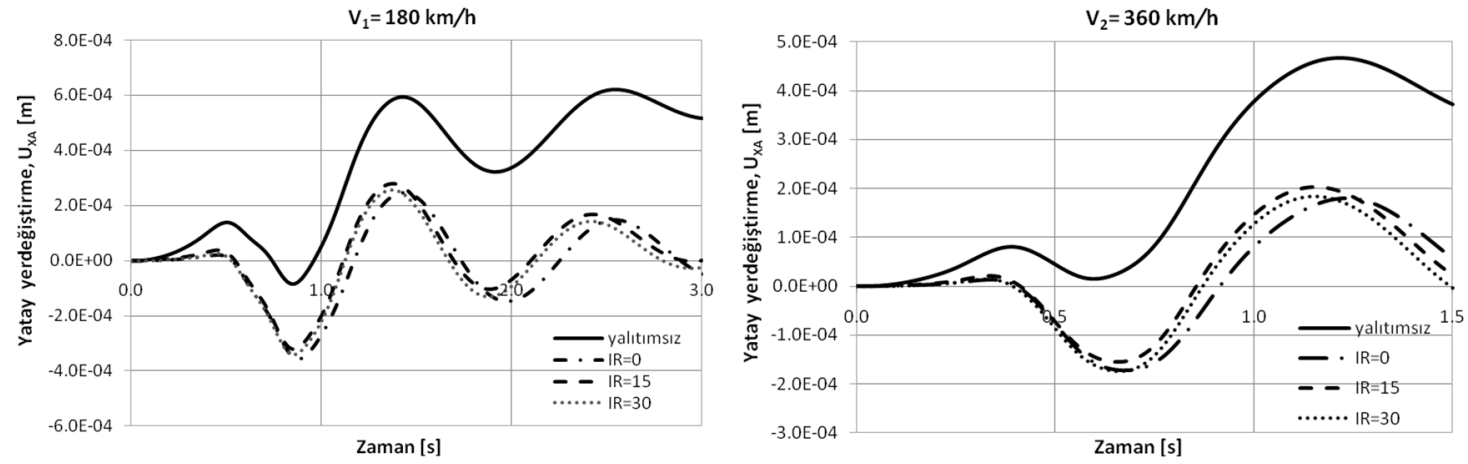

Şekil 6. Bina tepe noktası yatay yerdeğiştirmesinin zaman geçmişi (pasif yalıtım) (Time history of the horizontal roof displacement of the building for passive isolation)
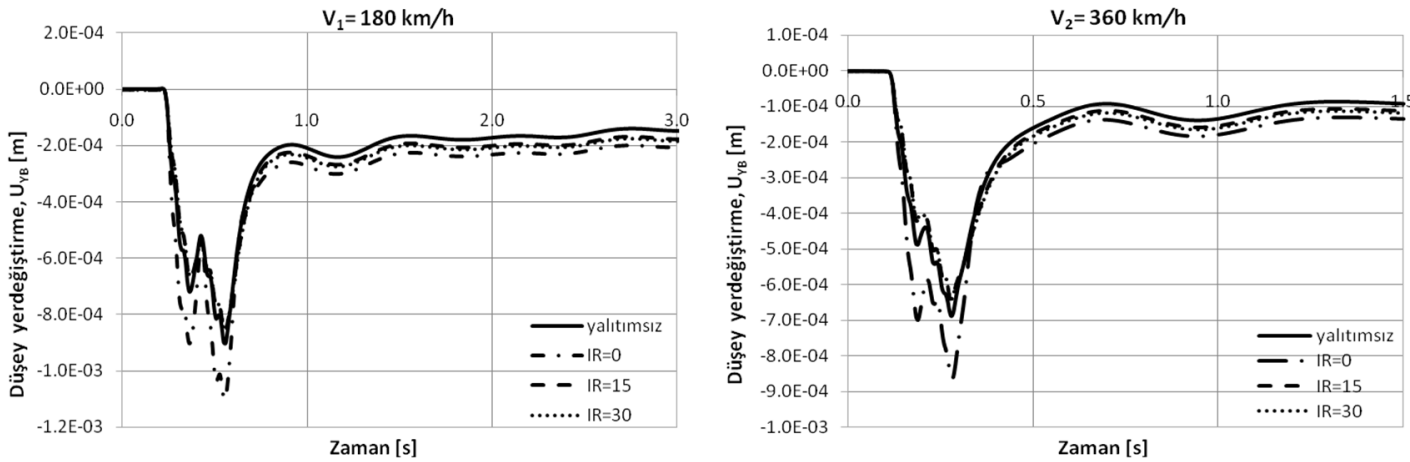

Şekil 7. Demiryolu üstyapısında oluşan düşey yerdeğiştirmenin zaman geçmişi (aktif yalıtım) (Time history of the vertical displacement on the railway embankment for active isolation)
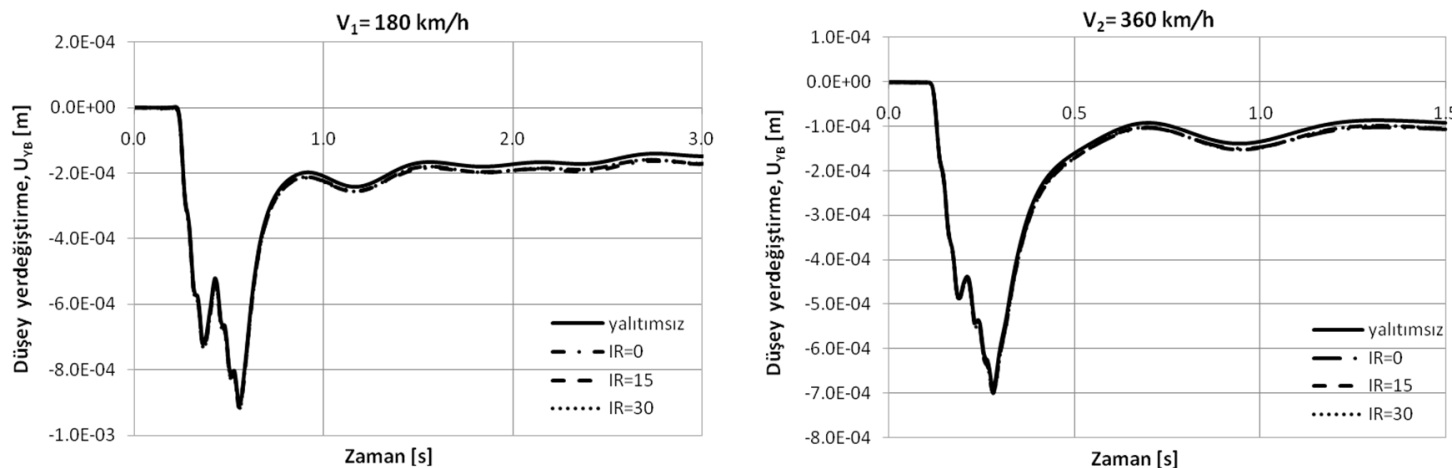

Şekil 8. Demiryolu üstyapısında oluşan düşey yerdeğiştirmenin zaman geçmişi (pasif yalıtım) (Time history of the vertical displacement on the railway embankment for passive isolation) 


\subsection{Yapay Taban Empedans Kontrastının ve Konumunun Yapısal Davranışa Etkisi (Effect of the Impedance and the Location of the Artificial Base on the Structural Response)}

Yapay taban kayanın yerleşim yerinin dalga yayılışına olan etkisi malzeme yoğunluk kontrastına (IR) bağlı incelenmiştir:

$I R=\frac{\rho_{b} V_{b}}{\rho_{s} V_{s}}$

Burada verilen yoğunluk kontrastı (IR) dalga engelleyici bariyerin empedans kontrast değerinin $\left(\rho_{\mathrm{b}} \mathrm{V}_{\mathrm{b}}\right)$, zemin bölgesinin empedans değerine $\left(\rho_{\mathrm{s}} \mathrm{V}_{\mathrm{s}}\right)$ oranı olarak tanımlanmaktadır. Yapılan sayısal analizler sonucunda bina tepe noktas 1 yatay deplasmanlarının empedans oranına $(\mathrm{IR}=0,15$ ve 30$)$ bağlı zaman geçmişleri, trenin $V_{1}=180 \mathrm{~km} / \mathrm{h}$ ve $\mathrm{V}_{2}=360 \mathrm{~km} / \mathrm{h}$ geçiş hızlarına göre aktif ve pasif yalıtım durumları için elde edilmiştir (Şekil 5-6). İçi boş kutu kesitli yatay dalga bariyerinin $(\mathrm{IR}=0)$ duvar stabilitesini sağlamak için $0,15 \mathrm{~m}$ genişliğinde betonarme cidar düşünülmüştür. Hızlı tren geçişlerinin demiryolu üst yapısında oluşturduğu düşey deplasmanların zamanla değişimleri taban kayanın aktif ve pasif yalıtım durumları için karşılaştırılmalı olarak verilmiştir (Şekil 7-8). Şekil 58 'un pratiğe dönük sonuçları ve önemli karakteristikleri aşağıda özetlenmiştir:

Aktif yalıtım durumunda göz önünde bulundurulan tüm dalga bariyer örnekleri $(0 \leq \mathrm{IR} \leq 30)$ binanın yatay titreşim genliklerini önemli derecede azaltılmıştır. Trenin $V_{1}=180 \mathrm{~km} / \mathrm{h}$ geçiş hızında $\mathrm{t}=1,4$ s'deki yer değiştirme genliklerinde içi boş bariyer modeli yalıtımsız duruma göre $\% 90$ civarında bina titreşimlerini azaltırken, diğer yalıtım modellerinde bu değer $\%$ 60'a kadar çıkmaktadır. Trenin $\mathrm{V}_{1}=360 \mathrm{~km} / \mathrm{h}$ geçiş hızında ortalama yalıtım performansı (IR $>0$ durumu için) \% 55 değerine kadar yükselmektedir. Yüksek frekanslarda dalgalar daha sığ ortamdan yayılımına devam ettiği için bütün yalıtım malzemelerinde yaklaşık olarak birbirine benzer davranış şekli gözlemlenmiştir. Pasif yalıtım uygulamasında hareketli yükün ele alınan geçiş hızları için farklı malzeme yoğunluğuna sahip tüm taban kaya yalıtım modellerinin binanın yatay titreşim genliklerinin azaltılmasında önemli derecede etkili olduğu görülmektedir. İçi boş betonarme kutu kesitli $(\mathrm{IR}=0)$, rijit $(\mathrm{IR}=30)$ ve yar1-rijit $(\mathrm{IR}=15)$ taban kaya uygulamaları, trenin $V_{1}=180 \mathrm{~km} / \mathrm{h}$ ve $V_{2}=360 \mathrm{~km} / \mathrm{h}$ geçiş hızları için binanın tepe noktasında meydana gelen yatay titreşim genliklerinin en büyük değerlerini yalıtımsız duruma göre ortalama olarak $1 / 3$ oranında azaltmıştır. Pasif yalıtım için gerçekleştirilen tüm sayısal uygulamalar dalga bariyerlerinin varlığının demiryolu üstyapı titreşimlerini önemli derecede etkilemediğini göstermiştir. Ancak aktif yalıtım durumunda taban kaya uygulaması titreşimlerin genliklerini $0,83 \mathrm{~mm}$ 'den $1,03 \mathrm{~mm}$ 'ye artırmıştır.

\section{SONUÇLAR (CONCLUSIONS)}

Yüksek hızlı trenlerin geçişi sırasında oluşturduğu büyük genlikli dalgaların yapılarda meydana getirdiği titreşim etkilerini azaltabilmek amacıyla, farklı tipteki yapay anakaya bariyer modelleri için kapsamlı parametrik çalışmalar gerçekleştirilmiştir. Araştırmalar doğrultusunda elde edilen genel sonuçlar aşağıdaki gibi özetlenebilir:

Dalga engelleyici yapay taban kayanın aktif yalıtım durumu için optimum boyutlar kullanılarak oluşturulan tüm bariyer modellerinin farklı geçiş hızlarında etkili olduğu ve içi boş bariyerin yalıtımsız duruma göre binalarda meydana gelen titreşim etkilerini önemli oranda azalttığı görülmüştür.

Yapay taban kaya modelinin pasif yalitım uygulamalarında en uygun bariyer boyutları kullanılarak imal edilen içi boş, rijit ve yarı-rijit bariyer modellerinin, binanın en üst katı düzeyinde oluşabilecek titreşim etkilerinin azaltılmasında etkili olduğu tespit edilmiştir.

Yapay anakaya bariyer modelleri ile gerçekleştirilen pasif yalıtım tedbirleri, demiryolu üstyap titreşimlerini önemli derecede değiştirmemiştir. Ancak aktif yalıtım durumunda taban kaya uygulaması titreşimlerin genliklerini ortalama olarak yalıtımsız duruma göre yaklaşı $\% 25$ civarında artırmaktadır.

Tren setlerinin yüksek seyahat hızlarıyla tekrarlı geçişleri sırasında zeminlerde ürettikleri yüksek frekanslı titreşimlerin çevre üst yapılardaki dinamik etkilerinin araştıılması ve azaltılması konusunda, ülkemizde yapı geoteknik ve ulaştırma mühendisliği disiplinlerinin planladığ detaylı bir ortak çalışma henüz yapılmamıştır. Mevcut araştırmaların sadece demiryolu üstyapı titreşimlerinin azaltılmasına yoğunlaşmış olması problemin geniş açıdan ve derinlemesine bakılmasına engel olmaktadır. Yüksek hız trenlerinin yerleşim bölgelerinden geçişi esnasında rahatsızlık verici titreşimlerin azaltılmasıyla ilgili uygun çözümlerin üretilmesi ve geliştirilen sayısal modellerin sunulması, bu özgün araştırmanın ulusal düzeyde uygulamaya dönük sonuçlarının katma değerini artıracaktır.

\section{KAYNAKLAR (REFERENCES)}

1. Ahmad, S., Al-Hussaini, T. M. ve Fishman, K. L., "An Investigation on Active Isolation of Machine Foundations by Open Trenches", J. Geotech. Eng., Cilt 122, No 6, 454-461, 1996.

2. Andersen, L. ve Nielsen, S. R. K., "Reduction of Ground Vibration by Means of Barriers or Soil Improvement along a Railway Track", Soil Dyn. Earthq. Eng., Cilt 25, No 7-10, 701-716, 2005. 
3. Çelebi, E., Kırtel, O. ve Aktaş, M., "Mitigation of The Effects of Vibrations Induced by High Speed Trains on Surrounding Buildings", Journal of the Faculty of Engineering and Architecture of Gazi University, Cilt 28, No 2, 321-332, 2013.

4. Yang, Y. ve Hung, H. "A Parametric Study of Wave Barriers for Reduction of Train-Induced Vibrations", Int. J. Numer. Meth. Eng., Cilt 40, No 20, 3729-3747, 1997.

5. Chouw, N., Le, R. ve Schmid, G., "Propagation of Vibration in a Soil Layer over Bedrock", Engineering Analysis with Boundary Elements, Cilt 8, No 3, 125-131, 1991.

6. Adam, M., Schmid, G. ve Chouw, N., "Investigation of Ground Motions and Structural Responses in Near Field due to Incident Waves", Proc. of 12th World Conference on Earthq. Eng., Auckland, New Zealand, 2000.

7. Ahmad, S. ve Al-Hussaini, T. M., "Simplified Design for Vibration Screening by Open and Infilled Trenches", J. Geotech. Eng., Cilt 117, No 1, 67-88, 1991.

8. Shen-H. J. ve Hung-Ta L., "Experimentally Investigating Finite Element Accuracy for Ground Vibration Induced by High-Speed Trains", Eng. Struct., Cilt 30, No 3, 733-746, 2008.

9. Celebi, E., Firat, S., Beyhan, G., Cankaya, I., Vural, I. ve Kirtel, O., "Field Experiments on Wave Propagations and Vibration Isolation by Using Wave Barriers", Soil Dyn. Earthq. Eng., Cilt 29, No 5, 824-833, 2009.

10. Forchap, E. ve Verbic, B., Wave Propagation and Reduction of Foundation Vibrations, BergVerlag GmbH, Bochum, 165-178, 1994.

11. Fuyuki, M. ve Matsumoto, Y., "Finite Difference Analysis of Rayleigh Wave Scattering at a Trench", Bull. Seism. Soc. America, Cilt 70, No 6, 2051-69, 1980.

12. Kausel, E., "Thin-Layer Method: Formulation in the Time Domain", Int. J. Numer. Meth. Eng., 37, 927-941, 1994.

13. Barber, J. R., "Surface Displacements due to a Steadily Moving Point Force", J. Appl. Mech., Cilt 63, No 2, 245-251, 1996.

14. Haupt, W. A., "Surface Waves in NonHomogeneous Half-Space", In Dynamical Methods in Soil and Rock Mechanics, Balkema, Rotterdam, 335-367, 1978.

15. Yang, B. Y. ve Hung, H. H., "A $2.5 \mathrm{D}$ Finite/Infinite Element Approach for Modelling Visco-Elastic Bodies Subjected to Moving Loads", Int. J. Numer. Meth. Eng., Cilt 240, No 1317-1336, 2001.

16. Leung, K. L. ve Beskos, D. E., Vardoulakis, I. G., "Vibration Isolation Using Open or Filled Trenches, Part 3: 2-D Non-Homg Soil", Comput. Mech., Cilt 7, No 2, 137-48. 1990.
17. Celebi, E. ve Schmid, G., "Investigation of Ground Vibrations Induced by Moving Loads", Eng. Struct., Cilt 27, No 14, 1981-1998, 2005.

18. Adam, M. ve Estorff, O. V., "Reduction of TrainInduced Building Vibrations by Using Open and Filled Trenches", Comput. Struct., 83, 11-24. 2005.

19. Karlström, A. ve Boström, A., "Efficiency of Trenches along Railways for Trains Moving at Sub- or Supersonic Speeds", Soil Dyn. Earthq. Eng., Cilt 27, No 7, 625-641, 2007.

20. Göktepe, F., Kırtel, O. ve Çelebi, E., "WIB for mitigation of structural responses to train induced vibrations", 9th Int. Cong on Adv in Civil Eng., KTU, Turkey, 2010.

21. Verbic, B., Über die rechnerische Untersuchung des Spannungs und Verformungszustandes im Oberbau und Unterbau der festen Fahrbahn infolge einer realen bewegter Last., Bericht, Ruhr Universität Bochum, 1996.

22. Huber, G., Erschütterungsausbreitung beim Rad/Schiene-system, Veröffentlichungen 115, Inst. für Bodenmechanik, Karlsruhe Universität, 1988.

23. Tosecky, A., Nümerische Untersuchung der Erschüterrungsausbreitung infolge bewegter Lasten auf einem Feste Fahrbahn-System mittels der Methode der dünnen Schichten/Methode der flexiblen Volumen, Diploma thesis, Ruhr Universität, Bochum, 2001.

24. Brinkgreve, R. B. J., Al-Khoury, R., Bakker, K. J., Bonnier, P. G., Brand, P. J. W., Broere, W., Burd, H. J., Soltys, G., Vermeer, P. A. ve Haag, D. D., Plaxis Finite Element Code for Soil and Rock Analyses, Published and Distributed by A.A. Balkema Publisher, The Netherlands, 2002.

25. Kuhlemeyer, R. L. ve Lysmer, J., "FEM Accuracy for Wave Propagation Problems", J. of Soil Mech. Found. Div., ASCE, Cilt 99, No SM5, 421-427, 1973.

26. Courant, R., Friedrichs, K. ve Lewy, H., "On the Partial Difference Equations of Mathematical Physics", IBM J.,Cilt 11, No 2, 215-234, 1967.

27. Lysmer, J. ve Kuhlemeyer, R. L., "Finite Dynamic Model for Infinite Media", J. of the Eng. Mech. Div., Cilt 95, No 4, 859-875, 1969.

28. Dasgupta, G., "A Finite Element Formulation for Unbounded Homogeneous Continua", J. Appl. Mech., Cilt 49, No 1, 136-140, 1982.

29. Wolf, J. P. ve Song, C., "Dynamic Stiffness Matrix of Unbounded Soil by Finite Element Multi-Cell Cloning", Earthq. Eng. Struct. Dyn., 23, 233-250, 1994.

30. Göktepe, F. ve Çelebi, E., "Non-linear 2-D FE analysis for the assessment of isolation performance of wave impeding barrier in reduction of railway-induced surface waves", Constr. Build. Mat., Cilt 36, No 2012, 1-13, 2012. 
31. Amick, H. ve Gendreau, M., "Construction vibrations and their impact on vibrationsensitive facilities", ASCE Construction Congress 6, Orlando, Florida USA, 2000.
32. Kim, D-S. ve Lee, J-S., "Source and attenuation characteristics of various ground vibrations", Geotech. Earthq. Eng., Soil Dyn. III., Geotech. Spec. Pub. ASCE, Cilt 75, No 2, 1507-1517, 1998. 